\title{
Optimization of SPE/GC/HPLC Analytical Procedure for Determination of Phenol, Quinones, and Carboxylic Acids in Water Samples
}

\author{
Katarzyna Bielicka-Daszkiewicz, Monika Hadzicka, and Adam Voelkel \\ Institute of Chemical Technology and Engineering, Poznań University of Technology, Pl. M.Skłodowskiej-Curie 2, \\ 60-965 Poznań, Poland \\ Correspondence should be addressed to Katarzyna Bielicka-Daszkiewicz, katarzyna.bielicka-daszkiewicz@put.poznan.pl
}

Received 20 March 2012; Accepted 3 May 2012

Academic Editors: M. C. Bruzzoniti, Y. Daali, and H. Naranmandura

Copyright (C 2012 Katarzyna Bielicka-Daszkiewicz et al. This is an open access article distributed under the Creative Commons Attribution License, which permits unrestricted use, distribution, and reproduction in any medium, provided the original work is properly cited.

\begin{abstract}
Chromatographic techniques are among the most useful analytical methods. Gas and liquid chromatography were used in the analysis of some organic compounds: phenol, hydroquinone, benzoquinone, and maleic and fumaric acids. The analytical way for the determination of these compounds in water samples was investigated. Solid-phase extraction (SPE) technique was used on the sample preparation step, different divinylbenzene-based sorbents were applied. Calibration curves of given compounds were linear over the ranges: $50-500 \mu \mathrm{g} / \mathrm{mL}$ for phenol and its acetic derivatives, $50-1500 \mu \mathrm{g} / \mathrm{mL}$ for benzoquinone in GC analysis, and $50-250 \mu \mathrm{g} / \mathrm{mL}$ for phenol, $40-1000 \mu \mathrm{g} / \mathrm{mL}$ for hydroquinone, and $4-4500 \mu \mathrm{g} / \mathrm{mL}$ for carboxylic acids in HPLC analysis. The LOD and LOQ of proposed analytical procedure were in the ranges of LOD: 0.042-23.83 $\mu \mathrm{g} / \mathrm{mL}$; LOQ: $0.138-78.64 \mu \mathrm{g} / \mathrm{mL}$.
\end{abstract}

\section{Introduction}

Phenol is a toxic compound, which very often appears in the industrial and municipal wastes. That is serious problem for the environment. There are many investigations striving for the scavenging, neutralization, and degradation of phenolic wastes and pollutants. Among the degradation techniques, the most popular are oxidation processes. There are catalytic oxidation, photodegradation, electrochemical oxidation, and degradation procedures using sonoelectrochemistry. These processes are widely described in the literature [1-11].

The main reaction route of the phenol oxidation is as follows: phenol $\rightarrow$ hydroquinone $\rightarrow$ benzoquinone $\rightarrow$ maleic acid and fumaric acid. The most desirable reaction way is the complete mineralization of phenol in which the endproducts are $\mathrm{H}_{2} \mathrm{O}$ and $\mathrm{CO}_{2}$. The oxidation can be stopped on different steps, so it is necessary to determine all products and byproducts of the reaction.

There are many analytical techniques used in the determination of phenol oxidation products and byproducts $[10,12-20]$. Chromatographic techniques are the most popular among analytical and separation methods. High performance liquid chromatography (HPLC) is very useful as water samples can be analyzed directly by this technique. However, not all compounds formed during oxidation of phenol and its derivatives can be precisely detected. The other technique useful in determination of phenol and its derivatives is gas chromatography (GC). In this technique the sample preparation step is considered essential, especially when water, medical, or environmental samples are analyzed. On these step extraction techniques, especially solid-phase extraction (SPE or SPME), is used, which is simple, relatively nonexpensive, and easy to proceed. Applying this technique makes a possibility of preconcentrating the sample, changing the solvent and cleaning the sample. Selection of proper analytical method and extraction conditions allows to achieve expected selectivity of the analytical procedure.

SPE technique is popular and practical separation method. The solid phase-sorbent-is the most important part of the extraction system. Polymeric sorbents are often used and their application is reported in various recently published papers [20-23]. The extraction recovery depends 
mostly on sorbent properties. These materials being stable in narrow $\mathrm{pH}$ range, are capable to extract polar and/or nonpolar compounds. The modification of monomers with different functional groups could change the extraction properties of the final sorbent. Therefore, it is possible to choose the most appropriate polymeric sorbent for a given application. The chemical nature of these polymers is different. Porous divinylbenzene copolymers are often used as SPE sorbents [20, 24-28]. Conducting polymers, for example aniline-based poly- $\mathrm{N}$-methylaniline or polydiphenylamine, have been also used for the preconcentration of phenolic compounds [29-31].

The aim of this work was to investigate the analytical procedure for qualitative and quantitative determination of phenol, hydroquinone, benzoquinone, maleic, and fumaric acids in water samples combining GC, HPLC, and SPE techniques. We have used reversed-phase HPLC and capillary GC. The preconcentration of organic compounds from water solutions was accomplished with standard and nonstandard SPE sorbents. Comparison of standard styrene-divinylbenzene polymeric sorbents (SDB1) and nonstandard divinylbenzene copolymers was made. Divinylbenzene copolymers with following monomers were used: 4,4'-bis(maleimido)diphenylmethane (BM), di(methacryloyloxymethyl)naphtalene (DMN), p, p'-dihydroxydiphenylmethane diglycidyl methacrylic ester (MEMDE), and $\mathrm{p}, \mathrm{p}^{\prime}$-dihydroxydiphenylpropane diglycidyl methacrylic ester (MEDDE).

\section{Experimental}

2.1. Chemicals. Methanol p.a., acetic anhydride p.a., dichloromethane p.a., $\mathrm{K}_{2} \mathrm{CO}_{3}$ anhydrous, pure and $\mathrm{HCl}$ pure were obtained from POCh (Gliwice, Poland). Chloroform p.a. was obtained from Merck (Darmstadt, Germany). Phenol (99\%), hydroquinone (99\%), benzoquinone (98\%), maleic and fumaric acids (99\%) were obtained from SigmaAldrich, Chimie GmbH (Steinheim, Germany).

Standard calibration solutions of phenol $(0.5-2 \mathrm{mg} / \mathrm{mL})$, hydroquinone $(0.1-1 \mathrm{mg} / \mathrm{mL})$, and benzoquinone $(0.8-$ $1.6 \mathrm{mg} / \mathrm{mL}$ ) for GC analysis were prepared in dichloromethane. Standard calibration solutions of phenol (0.025$4.05 \mathrm{mg} / \mathrm{mL})$, hydroquinone $(0.031-5.0 \mathrm{mg} / \mathrm{mL})$ and benzoquinone $\left(0.05 * 10^{-3}-1.5 \mathrm{mg} / \mathrm{mL}\right)$, and maleic acid $(0.004-$ $0.8 \mathrm{mg} / \mathrm{mL})$ and fumaric acids $(0.005-6.5 \mathrm{mg} / \mathrm{mL})$ for HPLC analysis were prepared in water.

Model samples of phenol, hydroquinone, benzoquinone, and acids were prepared by diluting $2 \mathrm{mg}$ of each compound in $25 \mathrm{~mL}$ of distilled (reversed osmotic) water. There were prepared separate samples for each examined compound and another one sample for all compounds together. $\mathrm{HCl}$ was used to adjust the $\mathrm{pH}$ of water samples in acidic range- to stabilize acids to stop the dissociation before HPLC analysis.

Phenol and hydroquinone are too polar for GC analysis on nonpolar capillary column and the derivatization process was made. Acetylation in water sample before extraction was performed. Compounds were dissolved in water samples, then $0.5 \mathrm{~g}$ of potassium carbonate $(\mathrm{pH}=11)$ and afterwards
$1 \mathrm{~mL}$ of acetic anhydride was added to the water sample and then the acetates were extracted with SPE. The extraction was carried out under alkaline conditions and phenol and hydroquinone are present in their dissociated forms what facilitates the acetylation process.

2.2. Equipment. Qualitative and quantitative analyses were made on gas chromatograph HP 5890II, capillary column MXT-5 (Restek) $0.25 \mu \mathrm{m}, 30 \mathrm{~m} \times 0.28 \mathrm{~mm}$, helium was used as carrier gas at flow rate $1.5 \mathrm{~mL} / \mathrm{min}$, and a head pressure of $150 \mathrm{kPa}$. Flame-ionization detector (FID) and split/splitless injector were used. Analyses were carried out in programmed temperature: the column temperature was held at initial temperature $60^{\circ} \mathrm{C}$ for $2 \mathrm{~min}$, then ramped at $10^{\circ} \mathrm{C} / \mathrm{min}$ to $125^{\circ} \mathrm{C}$, then at $70^{\circ} \mathrm{C} / \mathrm{min}$ to $250^{\circ} \mathrm{C}$ where it was held for $5 \mathrm{~min}$. Total analysis time was $15.30 \mathrm{~min}$.

For HPLC analysis HP 1100 chromatograph was used, analysis were made in reversed phase: C18 column $250 \times$ $4.6 \mathrm{~mm}$ ID (Restek) was used, acetonitrile were used as mobile phase at a flow rate $1 \mathrm{~mL} / \mathrm{min}$. UV-DAD detector was used for detection and identification of analytes. The column was thermostated during analysis at $45^{\circ} \mathrm{C}$, the analyses were carried out at isocratic condition.

2.3. SPE Procedure. Five porous polymers-divinylbenzene copolymers-were used as SPE sorbents:

(i) BM-DVB (sorbent mass: $193 \mathrm{mg}$ );

(ii) DMN-DVB (sorbent mass: $133 \mathrm{mg}$ );

(iii) MEDDE-DVB (sorbent mass:191 mg);

(iv) MEMDE-DVB (sorbent mass:170 mg);

(v) SDB-1 polystyrene-divinylbenzene, commercial polymeric sorbent was placed into polypropylene cartridges volume: $6 \mathrm{~mL}$, sorbent mass: $200 \mathrm{mg}$. (J. T. Baker, Deventer, Holland, supplied by Witko, Łódź, Poland).

Nonstandard polymeric materials: were synthesized by suspension copolymerization of 4, $4^{\prime}$-bis(maleimido) diphenylmethane (BM) and divinylbenzene (DVB) and by combined suspension-emulsion copolymerization of divinylbenzene (DVB) with di(methacryloxymethyl)naphthalene (DMN), p, $\mathrm{p}^{\prime}$-dihydroxydiphenylmethane diglycidyl methacrylic ester (MEMDE), p, $\mathrm{p}^{\prime}$-dihydroxydiphenylpropane diglycidyl methacrylic ester (MEDDE). Synthesis of monomers (BM, DMN, MEMDE, and MEDDE) and the extraction properties of divinylbenzene copolymers were described earlier in the literature $[28,32,33]$.

New synthesized polymeric resins were placed into $8 \mathrm{~mL}$ glass cartridges, produced by J. T. Baker (Deventer, Holland, supplied by Witko, Łódź, Poland). Sorbents mass are given above.

SPE procedure was evaluated earlier [27] and consist of the following steps:

(i) conditioning of the sorbent; (ii) isolation of the analytes; (iii) elution step. Methanol and water were used as the conditioning solvents in each extraction experiment (each 
TABLE 1: Correction factors, coefficient $\left(R^{2}\right), \mathrm{LOD}$, and linear range for different compounds determined in GC and HPLC analysis.

\begin{tabular}{|c|c|c|c|c|c|c|c|c|}
\hline \multirow{2}{*}{ Compounds } & \multicolumn{2}{|c|}{ Correction factor } & \multicolumn{2}{|c|}{$R^{2}$} & \multicolumn{2}{|c|}{$\mathrm{LOD}(\mu \mathrm{g} / \mathrm{mL})$} & \multicolumn{2}{|c|}{ Linear range $(\mu \mathrm{g} / \mathrm{mL})$} \\
\hline & GC & HPLC & GC & HPLC & GC & HPLC & GC & HPLC \\
\hline Phenol & $3.89 \mathrm{e}-7$ & $7.49 \mathrm{e}-4$ & 0.9998 & 0.9977 & 50.0 & 25.0 & $50-480$ & $50-250$ \\
\hline Phenol-acetic deriv. & $4.02 \mathrm{e}-7$ & - & 0.9976 & - & 50.0 & - & $50-500$ & - \\
\hline Hydroquinone & $4.79 \mathrm{e}-7$ & $6.12 \mathrm{e}-4$ & 1.000 & 0.9189 & - & 31.0 & - & $40-1000$ \\
\hline Hydroquinone-acetic deriv. & $4.74 \mathrm{e}-7$ & - & 0.9998 & - & 100.0 & - & $31-1000$ & - \\
\hline Benzoquinone & $7.66 \mathrm{e}-7$ & $8.67 \mathrm{e}-4$ & 0.9982 & 0.9996 & 50.0 & 0.05 & $50-1500$ & $0.2-200$ \\
\hline Maleic acid & - & $199.0 \mathrm{e}-4$ & - & 0.9994 & - & 2.00 & - & $4-4500$ \\
\hline Fumaric acid & - & $94.0 \mathrm{e}-4$ & - & 0.9988 & - & 5.00 & - & $5-2000$ \\
\hline
\end{tabular}

$10 \mathrm{~mL}$ ); dichloromethane and acetonitrile were used as the eluents $(3 \mathrm{~mL}$ and $5 \mathrm{~mL})$.

2.4. Analytical Procedure. The $2 \mathrm{mg} / 25 \mathrm{~mL}$ solutions were introduced on conditioned SPE sorbent, then sorbent was dried with the air and then sorbed compounds were eluted using 5 and $3 \mathrm{~mL}$ of organic solvents. The water sample after extraction was analyzed with HPLC while eluates were analyzed with GC. Water samples were derivatized before the extraction according to procedure described in Section 2.1. Water sample prepared without the derivatization step was analyzed simultaneously according the same analytical procedure.

\section{Results and Discussion}

\subsection{Qualitative and Quantitative Analysis}

3.1.1. Gas Chromatography (GC). In all samples, separated analytes were identified by comparing their retention data with that of standards.

In GC technique quantitative analysis based on external standard method was applied. It was prepared for each compound in different concentration ranges: $0-500 \mu \mathrm{g} / \mathrm{mL}$ for phenol, $0-500 \mu \mathrm{g} / \mathrm{mL}$ for acetic derivatives of phenol, $0-1000 \mu \mathrm{g} / \mathrm{mL}$ for acetic derivatives of hydroquinone, and $0-1500 \mu \mathrm{g} / \mathrm{mL}$ for benzoquinone. Calibration curves are linear in given ranges of concentration (Table 1). Correlation coefficients $\left(R^{2}\right)$, determined for each compound are between 0.9976 for phenol acetic derivatives and 0.9998 for nonderivatised phenol and hydroquinone acetic derivatives. Values of correction factor determined for analyzed compounds are given in the Table 1 .

3.1.2. Liquid Chromatography (HPLC). In HPLC technique quantitative analysis based on external standard method was applied. All standard solutions were made in acetonitrile. The calibration curve and correction factor was determined (Table 1); the linear range of the UV-DAD detector for each compound was determined. The analyses were made for 15 concentrations of the samples. Values of correlation coefficients $\left(R^{2}\right)$ are between 0.9189 for hydroquinone and 0.9996 for benzoquinone. The determined linearity are in narrow range of concentration $(0.2-200 \mu \mathrm{g} / \mathrm{mL}$ for benzoquinone, to $4-4500 \mu \mathrm{g} / \mathrm{mL}$ for maleic acid).
3.2. SPE Procedure. Different polymeric sorbents were used for the extraction. The extraction recovery was determined for each compound and compared in different systems. For benzoquinone the effectiveness of using 3 and $5 \mathrm{~mL}$ of two eluents (dichloromethane and acetonitrile) was compared (Figures 1(a) and 1(b)).

Recoveries achieved for different sorbents give similar trends: the best recovery is on SDB-1 sorbent (near 100\%), then on DMN-DVB (60-80\%) and BM-DVB (60-80\%). Recoveries on MEDDE-DVB and MEMDE-DVB sorbents are low (close to $40 \%$ ). Better results were achieved when $5 \mathrm{~mL}$ of dichloromethane was used as eluent. The water samples after SPE extraction were analyzed with HPLC for checking if there is any sorbents' breakthrough. The amounts of benzoquinone determined in the matrix after SPE (the post-SPE water sample) are presented in Figure 1(c). It is possible to notice the following dependence: the high extraction recovery on a given sorbent is accompanied with low content of benzoquinone in the post-SPE water sample (SDB-1), while for low recovery higher amount of benzoquinone in post-SPE water sample (MEDDEDVB, MEMDE-DVB) was determined. It means that the extraction of benzoquinone with the examined sorbents is not complete. It can result from small breakthrough volume of these sorbents. It was described in another article [34].

Other compounds present in the mixture-phenol and hydroquinone-were derivatized with acetic anhydride before the extraction. Therefore, it was necessary to compare the recovery of benzoquinone from water samples contain acetic anhydride with previous results (without acetic anhydride) (Figure 2(a)). The results show that the recovery in the presence of acetic anhydride are lower, and the amount of nonsorbed benzoquinone is higher (Figure 2(b)). However, the differences observed for standard sorbent (SDB-1) are insignificant.

The same comparison was done for the extraction of benzoquinone from the mixture of all compounds (phenol, hydroquinone, and acids), and when there was only benzoquinone in water sample. The results are similar.

When the mixture was extracted there were no acids in the eluates, but nearly whole amount of acids was detected in the post-SPE water samples (70-80\%). The extraction efficiency of water samples containing only acids was also examined. Maleic and fumaric acids were not retained on the polymeric sorbents or they were retained in very small 


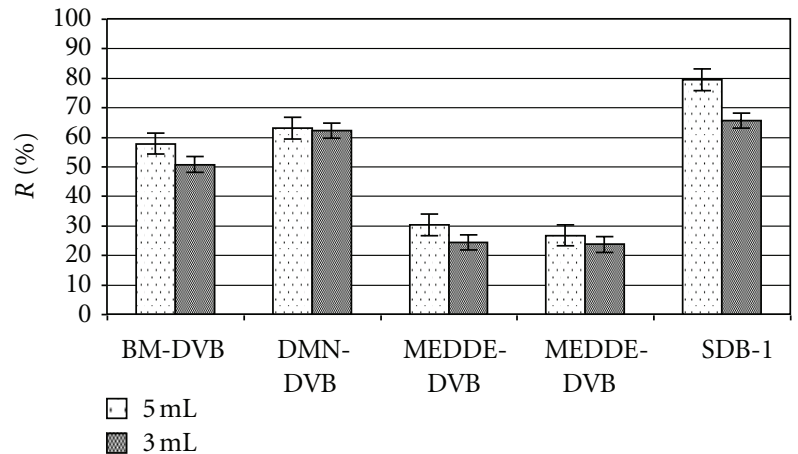

(a)

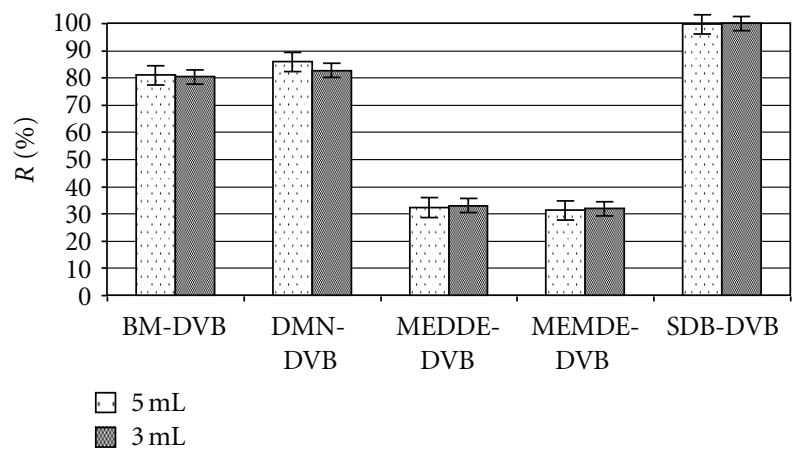

(b)

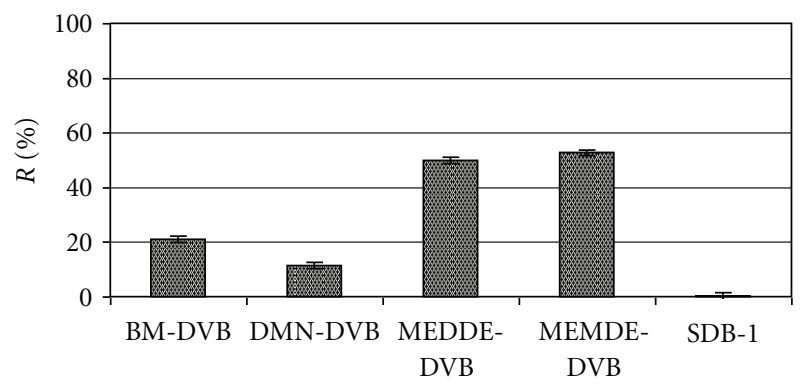

(c)

FIGURE 1: The extraction recovery of benzoquinone on different sorbents; (a) eluent: acetonitrile; (b) eluent: dichloromethane; (c) amount of benzoquinone in the post-SPE water samples.

amount, too small for the elution with dichloromethane and acetonitrile or the concentration of acids in the eluates was under detection limit. All amount of acids remained in water sample and it was determined using HPLC. The percentage of the initial content of each acid in original sample determined in post-SPE water samples is presented in Figure 3. The extraction recovery of phenol and hydroquinone derivatives was described earlier [27].

On the basis of experiments the new analytical SPE/GC/HPLC procedure was established. This procedure is presented in Figure 4.

The water sample containing the mixture of compounds (phenol, hydroquinone, benzoquinone, maleic acid, fumaric acid) was led to $\mathrm{pH} 11$ with $\mathrm{K}_{2} \mathrm{CO}_{3}$, then acetic anhydride was added for derivatization of phenol and hydroquinone. After this reaction water sample was introduced to the SPE

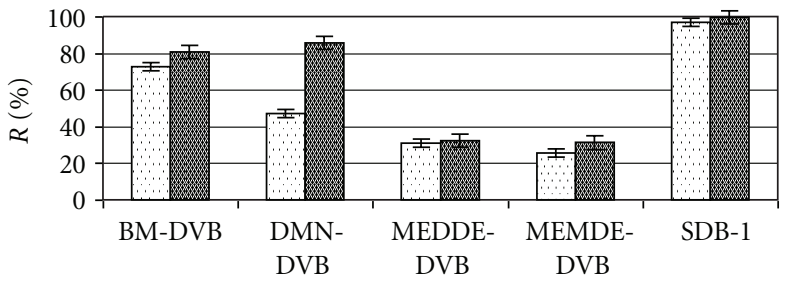

$\square$ Benzoquinone, acetic anhydride was in water sample 恛 Benzoquinone

(a) Concentration of benzoquinone in the eluent.

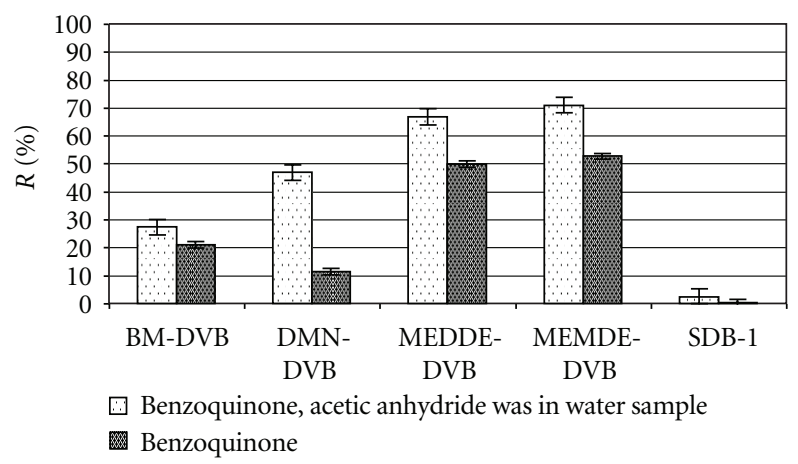

(b) Concentration of benzoquinone in the water matrix after SPE.

FIGURE 2: The recovery of benzoquinone in the presence of acetic anhydride and without anhydride (eluent $5 \mathrm{~cm}^{3}$ dichloromethane).

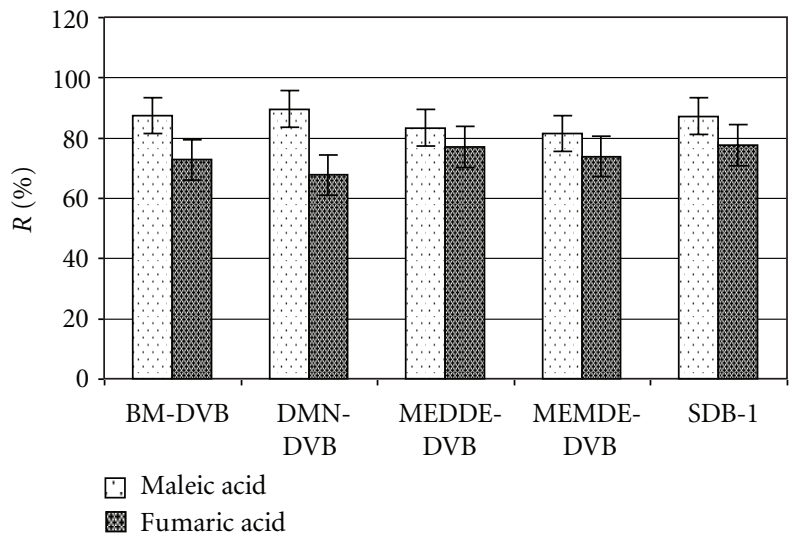

FIGURE 3: The percentage of initial content of acids determined in water matrix after SPE.

cartridge containing polymeric sorbent. Then the solid phase was dried with the air and sorbed compounds were eluted with $5 \mathrm{~cm}^{3}$ of dichloromethane. Eluate was analysed with gas chromatography to determine phenol and hydroquinone acetic derivatives and benzoquinone desorbed from polymeric phase. Water sample after extraction was analysed with liquid chromatography to determine nonsorbed amount of benzoquinone and main part of maleic and fumaric acid. Results are given in Table 2.

The efficiency of complete SPE/GC/HPLC analytical procedure is expressed by recovery and standard deviation for each compound. The recovery achieved on given sorbents are high for all compounds $70 \%$ to $100 \%$, only the recovery 
TABLE 2: Total recovery determined for each compound in SPE/GC/HPLC procedure.

\begin{tabular}{lcccccccccc}
\hline \multirow{2}{*}{ COMPOUND } & \multicolumn{2}{c}{ BM-DVB } & \multicolumn{2}{c}{ DMN-DVB } & \multicolumn{2}{c}{ MEDDE-DVB } & \multicolumn{2}{c}{ MEMDE-DVB } & \multicolumn{2}{c}{ SDB-1 } \\
& $(\%)$ & $\delta$ & $(\%)$ & $\delta$ & $(\%)$ & $\delta$ & $(\%)$ & $\delta$ & $(\%)$ \\
\hline Phenol-acetic deriv. & 92.27 & 1.51 & 89.37 & 3.06 & 64.65 & 0.72 & 50.35 & 1.90 & 100.19 & 5.22 \\
Hydroquinone-acetic deriv. & 49.07 & 4.91 & 49.08 & 5.21 & 38.21 & 5.23 & 34.70 & 3.20 & 48.88 & 4.14 \\
Benzoquinone & 98.97 & 2.20 & 90.74 & 3.77 & 91.21 & 5.14 & 84.92 & 1.75 & 102.82 & 2.12 \\
Maleic acid & 87.26 & 1.53 & 89.50 & 1.49 & 83.30 & 1.60 & 81.42 & 1.64 & 87.13 & 1.53 \\
Fumaric acid & 72.70 & 5.54 & 67.58 & 8.39 & 76.92 & 4.18 & 73.77 & 8.11 & 77.47 & 7.54 \\
\hline
\end{tabular}

$\delta:$ standard deviation.

TABLE 3: LOD and LOQ determined for each compound in SPE/GC/HPLC procedure taking the recovery on SPE sorbents into consideration ( $\mu \mathrm{g} / \mathrm{mL}$ of water sample).

\begin{tabular}{lcccccccrrr}
\hline \multirow{2}{*}{ COMPOUND } & \multicolumn{2}{c}{ BM-DVB } & \multicolumn{2}{c}{ DMN-DVB } & \multicolumn{2}{c}{ MEDDE-DVB } & \multicolumn{2}{c}{ MEMDE-DVB } & \multicolumn{2}{c}{ SDB-1 } \\
& LOD & LOQ & LOD & LOQ & LOD & LOQ & LOD & LOQ & LOD & LOQ \\
\hline Phenol-acetic deriv. & 13.00 & 42.92 & 13.43 & 44.31 & 18.56 & 61.25 & 23.83 & 78.65 & 11.98 & 39.52 \\
Hydroquinone-acetic deriv. & 16.71 & 55.15 & 16.71 & 55.13 & 21.46 & 70.82 & 23.63 & 78.00 & 16.78 & 55.36 \\
Benzoquinone & 0.043 & 0.143 & 0.044 & 0.156 & 0.047 & 0.155 & 0.050 & 0.165 & 0.042 & 0.138 \\
Maleic acid & 4.58 & 15.13 & 4.47 & 14.75 & 4.80 & 15.85 & 4.91 & 16.21 & 4.59 & 15.15 \\
Fumaric acid & 6.88 & 22.37 & 7.40 & 24.41 & 6.50 & 21.45 & 6.78 & 22.37 & 6.45 & 21.30 \\
\hline
\end{tabular}

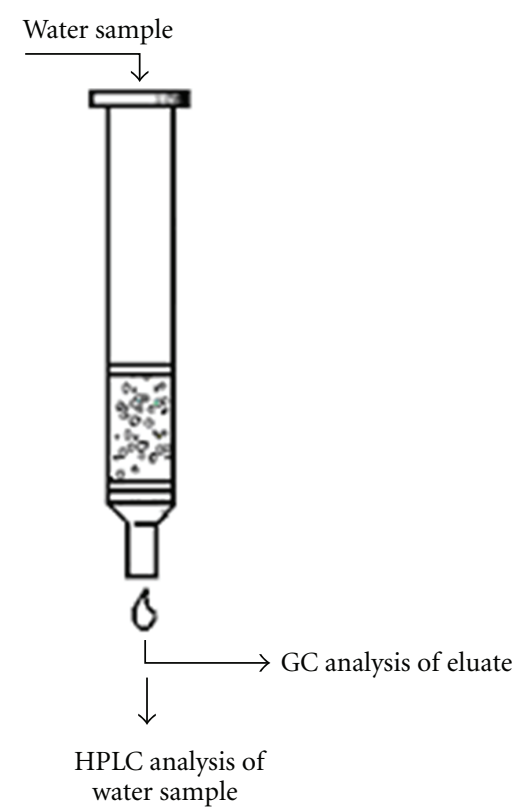

FIgure 4: The SPE/GC/HPLC procedure.

of hydroquinone acetic derivatives are lower than $50 \%$. Comparing the extraction properties of given sorbents, we can see that copolymers of DVB with diglycidyl metacrylic esters (MEDDE and MEMDE) are less efficient in the extraction of phenol and its oxidation products. It is connected with relationships between the recovery and physical and chemical properties of sorbents-surface area, particle size, pore size, pore volume, polarity, polymer structure (the length of chemical chains). These relationships were widely described in the article [28]. Copolymers: MEDDEDVB and MEMDE-DVB are the most polar among tested sorbents, these sorbents have relatively large pore volume $\left(0.33 \mathrm{~cm}^{3} / \mathrm{g}\right.$ for MEDDE-DVB and $0.36 \mathrm{~cm}^{3} / \mathrm{g}$ for MEMDEDVB) but small surface area $\left(20 \mathrm{~m}^{2} / \mathrm{g}\right.$ for MEDDE-DVB and $70 \mathrm{~cm}^{2} / \mathrm{g}$ for MEMDE-DVB, while these parameters for SDB-1 sorbent are $0.77 \mathrm{~cm}^{3} / \mathrm{g}$ and $966 \mathrm{~cm}^{2} / \mathrm{g}$ ). The weak extraction properties of these sorbents for given compounds can be connected with the chemical structure of the polymer. There are long diglycidyl chains in the structure, which can indicate large pore size and low compounds' retention on these sorbents.

3.3. $L O D$ and $L O Q$. LOD value corresponds to a minimum detectable signal that can be detected from the fluctuations of the chromatographic background line. LOQ value corresponds to a concentration for which the repeatability of quantitative determination is below 5\%. In GC analysis, LOD (minimum detectable signal) is equal to $k$ times standard deviation which expressed the fluctuation of the background chromatographic line [35]. The value of $k$ is 3 .

Limit of detection (LOD) and linear range in GC and HPLC analysis for individual compound were determined with standard solution, the values are given in the Table 1 . Now we can determine LOD and LOQ for established SPE/GC/HPLC analytical procedure. The LOD and LOQ values are given in the Table 3 . Each analysis was repeated five times $(n=5)$. LOD was calculated based on signal-to-noise ratio of 3. The most detectable compound is benzoquinone, it can be analyzed in the broadest concentration range, the LOD and LOQ have the lowest values (LOD $=0.043 \mu \mathrm{g} / \mathrm{mL}$, LOQ $=0.138 \mu \mathrm{g} / \mathrm{mL}$ ). The lower LOD and LOQ values are for phenol and hydroquinone acetic derivatives. The LOD 
and LOQ values for carboxylic acids are between 4.58$6.88 \mu \mathrm{g} / \mathrm{mL}$ (LOD) and between 14.75-24.41 $\mu \mathrm{g} / \mathrm{mL}$ (LOQ).

\section{Conclusion}

Connection of chromatographic techniques increases the effectiveness of the analysis of the mixture of organic compounds. The use of SPE technique on the sample preparation step is suitable for good separation of phenol, hydroquinone, benzoquinone, and dicarboxylic acids (maleic and fumaric acid). This improves the quantitative analysis of these compounds. The derivatization process on the sample preparation step before the chromatographic analysis enables appropriate separation of compounds. The conversion of phenol and hydroquinone into less polar derivatives leads to better results of GC analysis-good separation and qualitative and quantitative analyses. The HPLC analysis is appropriate for the determination of compounds in water sample not extracted on the solid phase. In this way one can estimate the efficiency of SPE/GC analysis, it is possible to check if the isolation of examined compounds was complete.

Comparing the extraction properties of standard and nonstandard polymeric sorbents we can observe that copolymers of divinylbenzene with other monomers than styrene not improved the extraction properties. Comparison of the results given in Tables 2 and 3 shows that recoveries achieved on nonstandard polymeric sorbents (especially for BM-DVB and DMN-DVB) are close to that achieved by using SDB-1 and the repeatability is satisfactory.

The investigated SPE/GC/HPLC procedure is efficient for the examination of mixtures of compounds described in this work, what has been proved by LOD and LOQ values. It can be used in the broad concentration range.

\section{Acknowledgment}

This work was supported by 32-045/12 DS-PB.

\section{References}

[1] M. A. Gondal and Z. Seddigi, "Laser-induced photo-catalytic removal of phenol using n-type $\mathrm{WO}_{3}$ semiconductor catalyst," Chemical Physics Letters, vol. 417, no. 4-6, pp. 124-127, 2006.

[2] H. Kušić, N. Koprivanac, A. L. Božić, and I. Selanec, "Photoassisted fenton type processes for the degradation of phenol: a kinetic study," Journal of Hazardous Materials, vol. 136, no. 3, pp. 632-644, 2006.

[3] S. G. Poulopoulos, F. Arvanitakis, and C. J. Philippopoulos, "Photochemical treatment of phenol aqueous solutions using ultraviolet radiation and hydrogen peroxide," Journal of Hazardous Materials, vol. 129, no. 1, pp. 64-68, 2006.

[4] B. Tryba, A. W. Morawski, M. Inagaki, and M. Toyoda, "Mechanism of phenol decomposition on $\mathrm{FeCTiO}_{2}$ and $\mathrm{FeTiO}_{2}$ photocatalysts via photo-fenton process," Journal of Photochemistry and Photobiology A, vol. 179, no. 3, pp. 224-228, 2006.

[5] Y. Yavuz and A. S. Koparal, "Electrochemical oxidation of phenol in a parallel plate reactor using ruthenium mixed metal oxide electrode," Journal of Hazardous Materials, vol. 136, no. 2, pp. 296-302, 2006.

[6] N. N. Mahamuni and A. B. Pandit, "Effect of additives on ultrasonic degradation of phenol," Ultrasonics Sonochemistry, vol. 13, no. 2, pp. 165-174, 2006.

[7] R. H. Lima Leite, P. Cognet, A.-M. Wilhelm, and H. Delmas, "Anodic oxidation of 2,4-dihydroxybenzoic acid for wastewater treatment: study of ultrasound activation," Chemical Engineering Science, vol. 57, no. 5, pp. 767-778, 2002.

[8] V. Arutchelvan, V. Kanakasabai, R. Elangovan, S. Nagarajan, and V. Muralikrishnan, "Kinetics of high strength phenol degradation using Bacillus brevis," Journal of Hazardous Materials, vol. 129, no. 1-2, pp. 216-222, 2006.

[9] K. M. Khleifat, "Biodegradation of phenol by Ewingella americana: effect of carbon starvation and some growth conditions," Process Biochemistry, vol. 41, no. 9, pp. 2010-2016, 2006.

[10] S. Abaci, U. Tamer, K. Pekmez, and A. Yildiz, "Performance of different crystal structures of $\mathrm{PbO}_{2}$ on electrochemical degradation of phenol in aqueous solution," Applied Surface Science, vol. 240, no. 1-4, pp. 112-119, 2005.

[11] E. Gonze, L. Fourel, Y. Gonthier, P. Boldo, and A. Bernis, "Wastewater pretreatment with ultrasonic irradiation to reduce toxicity," Chemical Engineering Journal, vol. 73, no. 2, pp. 93-100, 1999.

[12] S. Esplugas, J. Giménez, S. Contreras, E. Pascual, and M. Rodríguez, "Comparison of different advanced oxidation processes for phenol degradation," Water Research, vol. 36, no. 4, pp. 1034-1042, 2002.

[13] H. Chung, W. Yizhong, and T. Hongxiao, "Destruction of phenol aqueous solution by photocatalysis or direct photolysis," Chemosphere, vol. 41, no. 8, pp. 1205-1209, 2000.

[14] M. A. Maluleke and V. M. Linkov, "Partial electrochemical oxidation of phenol on ceramic-based flat-sheet type electromembrane reactors," Separation and Purification Technology, vol. 32, no. 1-3, pp. 377-385, 2003.

[15] Z. P. G. Masende, B. F. M. Kuster, K. J. Ptasinski, F. J. J. G. Janssen, J. H. Y. Katima, and J. C. Schouten, "Platinum catalysed wet oxidation of phenol in a stirred slurry reactor: the role of oxygen and phenol loads on reaction pathways," Catalysis Today, vol. 79-80, pp. 357-370, 2003.

[16] R.-M. Liou, S.-H. Chen, M.-Y. Hung, C.-S. Hsu, and J.Y. Lai, "Fe (III) supported on resin as effective catalyst for the heterogeneous oxidation of phenol in aqueous solution," Chemosphere, vol. 59, no. 1, pp. 117-125, 2005.

[17] B. Roig, C. Gonzalez, and O. Thomas, "Monitoring of phenol photodegradation by ultraviolet spectroscopy," Spectrochimica Acta A, vol. 59, no. 2, pp. 303-307, 2003.

[18] L. Noreña-Franco, I. Hernandez-Perez, J. Aguilar-Pliego, and A. Maubert-Franco, "Selective hydroxylation of phenol employing Cu-MCM-41 catalysts," Catalysis Today, vol. 75, no. 1-4, pp. 189-195, 2002.

[19] M. H. Zareie, B. K. Körbahti, and A. Tanyolaç, "Nonpassivating polymeric structures in electrochemical conversion of phenol in the presence of $\mathrm{NaCl}$," Journal of Hazardous Materials, vol. 87, no. 1-3, pp. 199-212, 2001.

[20] N. Fontanals, P. Puig, M. Galià, R. M. Marcé, and F. Borrull, "New hydrophilic polymeric resin based on 4-vinylpyridinedivinylbenzene for solid-phase extraction of polar compounds from water," Journal of Chromatography A, vol. 1035, no. 2, pp. 281-284, 2004.

[21] A. Li, Q. Zhang, G. Zhang, J. Chen, Z. Fei, and F. Liu, "Adsorption of phenolic compounds from aqueous solutions by 
a water-compatible hypercrosslinked polymeric adsorbent," Chemosphere, vol. 47, no. 9, pp. 981-989, 2002.

[22] T. Prasada Rao, R. S. Praveen, and S. Daniel, "Styrenedivinylbenzene copolymers: synthesis, characterization, and their role in inorganic trace analysis," Critical Reviews in Analytical Chemistry, vol. 34, no. 3-4, pp. 177-193, 2004.

[23] N. Fontanals, M. Galià, P. A. G. Cormack, R. M. Marcé, F. D. C. Sherrington, and F. Borrull, "Evaluation of a new hypercrosslinked polymer as a sorbent for solid-phase extraction of polar compounds," Journal of Chromatography A, vol. 1075, no. 1-2, pp. 51-56, 2005.

[24] N. Fontanals, M. Galià, R. M. Marcé, and F. Borrull, "Solidphase extraction of polar compounds with a hydrophilic copolymeric sorbent," Journal of Chromatography A, vol. 1030, no. 1-2, pp. 63-68, 2004.

[25] S. Le Moullec, L. Truong, C. Montauban, A. Begos, V. Pichon, and B. Bellier, "Extraction of alkyl methylphosphonic acids from aqueous samples using a conventional polymeric solidphase extraction sorbent and a molecularly imprinted polymer," Journal of Chromatography A, vol. 1139, no. 2, pp. 171$177,2007$.

[26] G. Theodoridis, C. K. Zacharis, P. D. Tzanavaras, D. G. Themelis, and A. Economou, "Automated sample preparation based on the sequential injection principle: solid-phase extraction on a molecularly imprinted polymer coupled online to high-performance liquid chromatography," Journal of Chromatography A, vol. 1030, no. 1-2, pp. 69-76, 2004.

[27] K. Bielicka-Daszkiewicz, M. Dębicka, and A. Voelkel, "Comparison of three derivatization ways in the separation of phenol and hydroquinone from water samples," Journal of Chromatography A, vol. 1052, no. 1-2, pp. 233-235, 2004.

[28] K. Bielicka-Daszkiewicz, A. Voelkel, M. Szejner, and J. Osypiuk, "Extraction properties of new polymeric sorbents in SPE/GC analysis of phenol and hydroquinone from water samples," Chemosphere, vol. 62, no. 6, pp. 890-898, 2006.

[29] H. Bagheri and M. Saraji, "Conductive polymers as new media for solid-phase extraction: isolation of chlorophenols from water sample," Journal of Chromatography A, vol. 986, no. 1, pp. 111-119, 2003.

[30] H. Bagheri, A. Mohammadi, and A. Salemi, "On-line trace enrichment of phenolic compounds from water using a pyrrole-based polymer as the solid-phase extraction sorbent coupled with high-performance liquid chromatography," Analytica Chimica Acta, vol. 513, no. 2, pp. 445-449, 2004.

[31] H. Bagheri and M. Saraji, "New polymeric sorbent for the solid-phase extraction of chlorophenols from water samples followed by gas chromatography-electron-capture detection," Journal of Chromatography A, vol. 910, no. 1, pp. 87-93, 2001.

[32] B. Gawdzik, T. Matynia, and J. Osypiuk, "Porous copolymer of the methacrylic ester of dihydroxydiphenylmethane diglycidyl ether and divinylbenzene as an HPLC packing," Chromatographia, vol. 47, no. 9-10, pp. 509-514, 1998.

[33] B. Gawdzik and J. Osypiuk, "Reversed-phase highperformance liquid chromatography on porous copolymers of different chemical structure," Journal of Chromatography A, vol. 898, no. 1, pp. 13-21, 2000.

[34] K. Bielicka-Daszkiewicz and A. Voelkel, "Theoretical and experimental methods of determination of the breakthrough volume of SPE sorbents," Talanta, vol. 80, no. 2, pp. 614-621, 2009.

[35] M. Carré, S. Excoffier, and J. M. Mermet, "A study of the relation between the limit of detection and the limit of quantitation in inductively coupled plasma spectrochemistry," Spectrochimica Acta B, vol. 52, no. 14, pp. 2043-2049, 1997. 


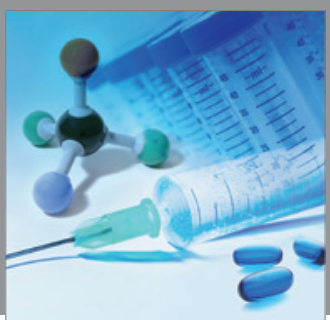

International Journal of

Medicinal Chemistry

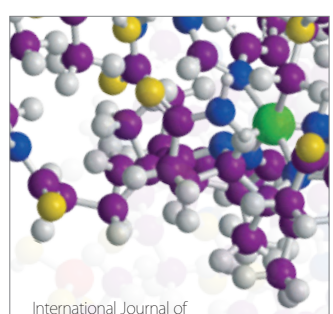

Carbohydrate Chemistry

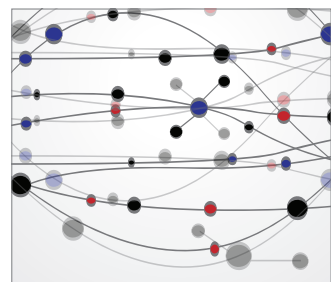

The Scientific World Journal
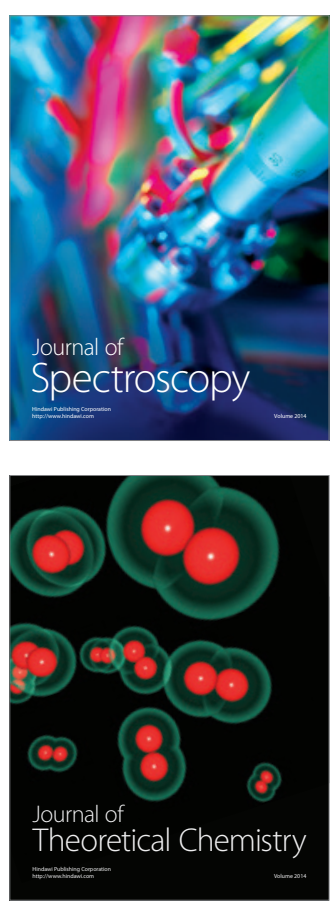
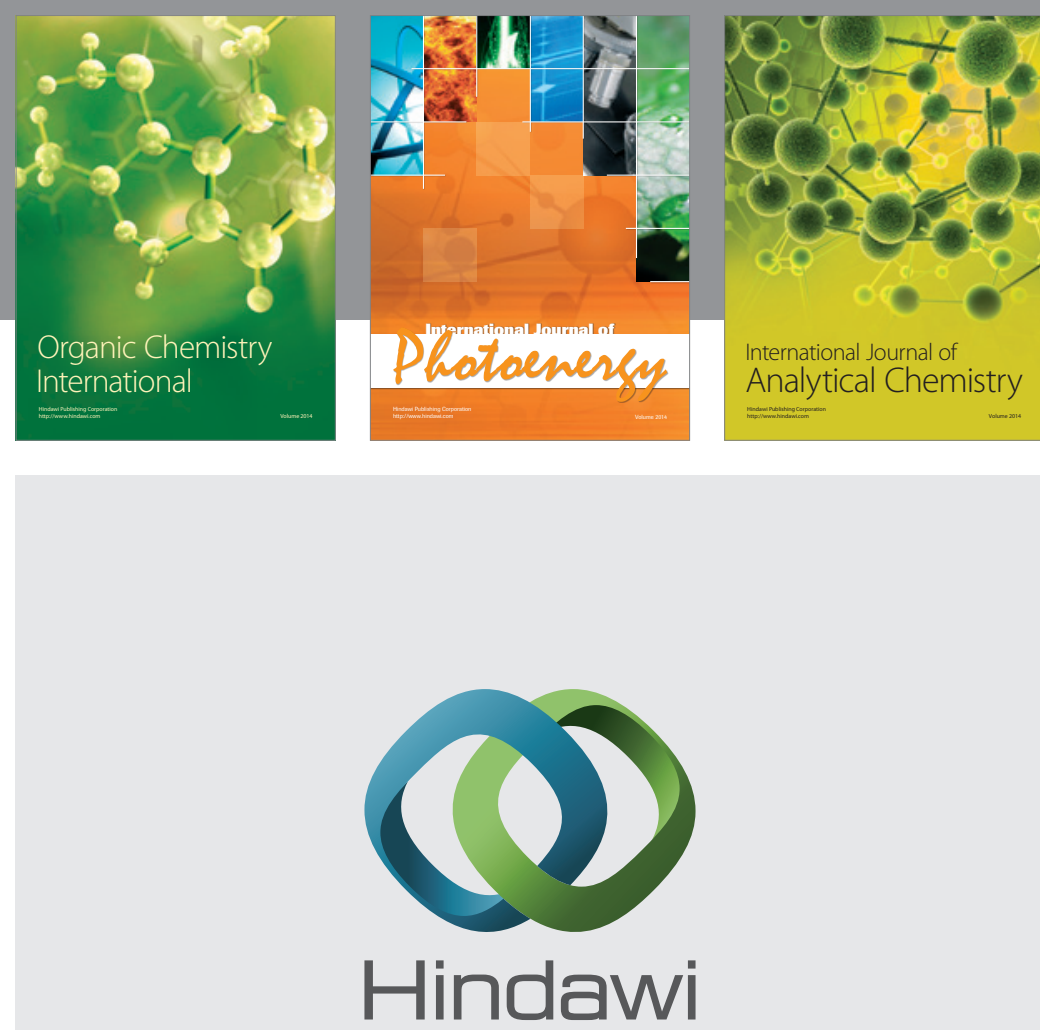

Submit your manuscripts at

http://www.hindawi.com
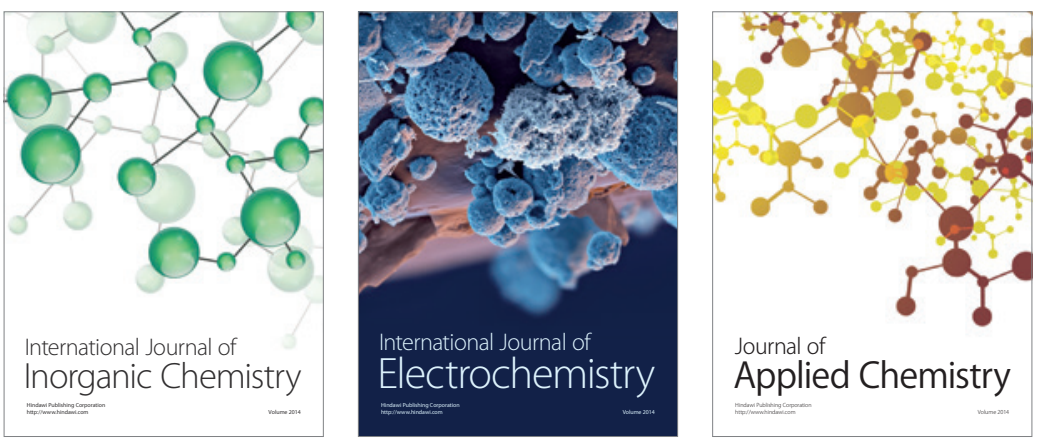

Journal of

Applied Chemistry
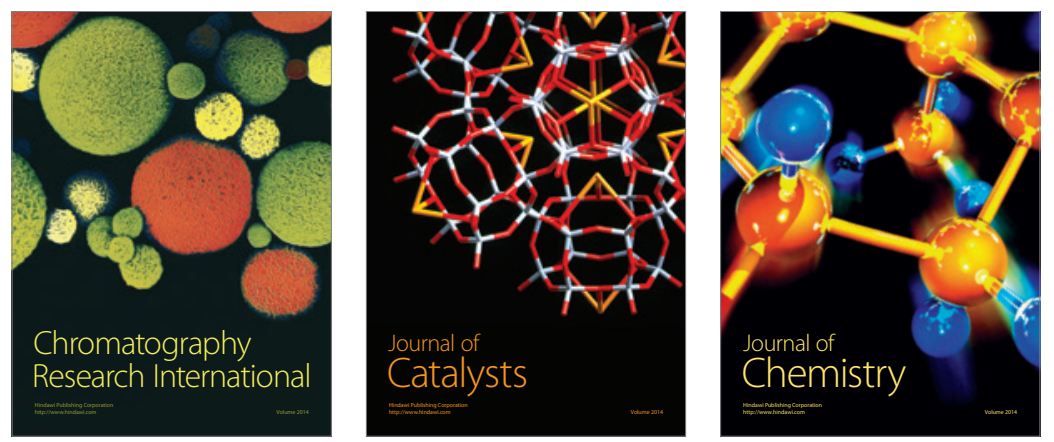
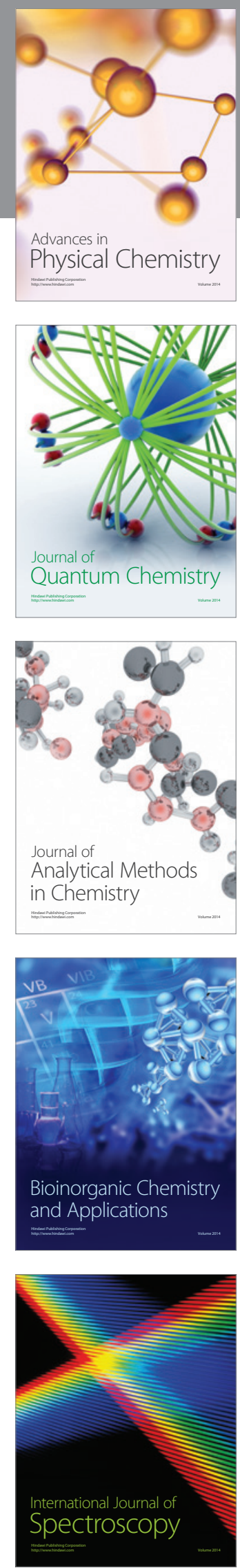